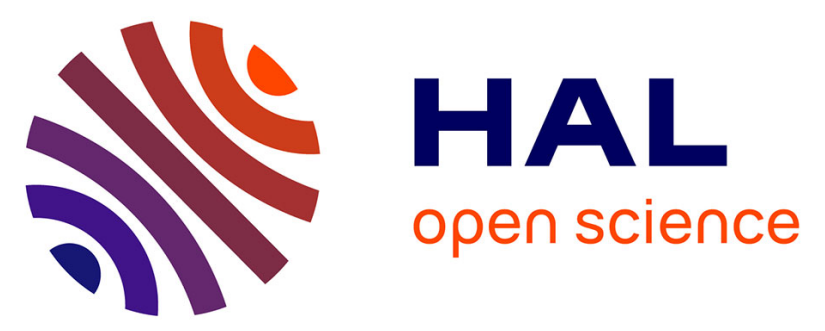

\title{
Influence of the reactive atmosphere on the formation of nanoparticles in the plasma plume induced by nanosecond pulsed laser irradiation of metallic targets at atmospheric pressure and high repetition rate
}

M. Girault, Jean-Luc Le Garrec, James Brian Alexander Mitchell, J. -M. Jouvard, Erwann Carvou, Jérôme Menneveux, J. Yu, F. -X. Ouf, Sophie Carles, V. Potin, et al.

\section{- To cite this version:}

M. Girault, Jean-Luc Le Garrec, James Brian Alexander Mitchell, J. -M. Jouvard, Erwann Carvou, et al.. Influence of the reactive atmosphere on the formation of nanoparticles in the plasma plume induced by nanosecond pulsed laser irradiation of metallic targets at atmospheric pressure and high repetition rate. Applied Surface Science, 2016, 374, pp.132-137. 10.1016/j.apsusc.2015.10.090 . hal-01225623

HAL Id: hal-01225623

https://hal-univ-rennes1.archives-ouvertes.fr/hal-01225623

Submitted on 27 Jan 2016

HAL is a multi-disciplinary open access archive for the deposit and dissemination of scientific research documents, whether they are published or not. The documents may come from teaching and research institutions in France or abroad, or from public or private research centers.
L'archive ouverte pluridisciplinaire HAL, est destinée au dépôt et à la diffusion de documents scientifiques de niveau recherche, publiés ou non, émanant des établissements d'enseignement et de recherche français ou étrangers, des laboratoires publics ou privés. 
Influence of the reactive atmosphere on the formation of nanoparticles in the plasma plume induced by nanosecond pulsed laser irradiation of metallic targets at atmospheric pressure and high repetition rate

M. Girault ${ }^{\mathrm{a}}$, J.-L. Le Garrec ${ }^{\mathrm{b}}$, J. B. A. Mitchell ${ }^{\mathrm{b}}$, J.-M. Jouvard ${ }^{\mathrm{a}}$, E. Carvou ${ }^{\mathrm{b}}$ J. Menneveux ${ }^{\mathrm{c}}$, J. Yu ${ }^{\mathrm{c}}$, F.-X. Ouf ${ }^{\mathrm{d}}$, S. Carles ${ }^{\mathrm{b}}$, V. Potin ${ }^{\mathrm{a}}$, G. Pillon ${ }^{\mathrm{a}}, \mathrm{S}$. Bourgeois $^{\text {a }}$,J. Perez ${ }^{\mathrm{e}}$, M. C. Marco de Lucas ${ }^{\mathrm{a}, *}$, L. Lavisse ${ }^{\mathrm{a}, *}$

${ }^{a}$ Laboratoire Interdisciplinaire Carnot de Bourgogne, UMR 6303 CNRS-Univ. Bourgogne Franche-Comté, 9 Av. A. Savary, BP 47870 , F-21078 DIJON Cedex, France. Institut de Physique de Rennes, UMR 6251 CNRS-Université de Rennes 1, 35042 Rennes

Cedex, France
${ }^{C}$ Institut Lumière Matière, UMR5306 Université Lyon 1-CNRS, Université de Lyon, 69622 Villeurbanne Cedex, France

${ }^{d}$ Institut de Radioprotection et de Sureté Nucléaire IRSN/PSN-RES/SCA/LPMA BP 68 1192 Gif Sur Yvette, France

${ }^{e}$ Synchrotron SOLEIL, L'Orme des Merisiers, Saint-Aubin, F-91192 Gif-sur-Yvette Cedex France

\section{Abstract}

The influence of a reactive atmosphere on the formation of nanoparticles (NPs) in the plasma plume generated by nanosecond pulsed laser irradiation of metal targets $(\mathrm{Ti}, \mathrm{Al}, \mathrm{Ag})$ was probed in-situ using Small Angle X-ray Scattering (SAXS). Air and different $\mathrm{O}_{2}-\mathrm{N}_{2}$ gas mixtures were used as reactive gas within atmospheric pressure. SAXS results showed the formation of NPs in the plasmaplume with a mean radius varying in the $2-5 \mathrm{~nm}$ range. A decrease of the NPs size with increasing the $\mathrm{O}_{2}$ percentage in the $\mathrm{O}_{2}-\mathrm{N}_{2}$ gas mixture was also showed. Ex-situ observations by transmission electron microscopy and structural characterizations by x-ray diffraction and Raman spectroscopy were also performed for powders collected in experiments done using air as ambient gas. The stability of the different metal oxides is discussed as being a key parameter influencing

Corresponding authors

Email addresses: delucas@u-bourgogne.fr (M. C. Marco de Lucas), luc.lavisse@u-bourgogne.fr (L. Lavisse)

October 19, 2015 
the formation of NPs in the plasma-plume.

Keywords: Laser ablation, SAXS, metal oxides stability, nanoparticles.

\section{Introduction}

Laser treatments are powerful tools for many technological processes such as welding, cleaning and marking. The formation of nanoparticles (NPs) is usually observed in metal targets irradiated by pulsed laser sources with a pulse duration less than a few tens of nanoseconds $[1,2,3,4,5]$. The ablation mechanism which is the origin of the NPs formation strongly depends on the laser pulse duration.

In nanosecond laser ablation, the expansion of the plasma plume formed above the target can be quenched by the ambient gas at a high enough pressure giving rise to the formation of NPs. The composition and the pressure of the ambient gas strongly influence the properties of the NPs thus formed $[4,3]$.

In this range, the absorption of the laser beam in both the target surface and the plasma-plume formed above the target surface by surface vaporization strongly depends on the laser wavelength. On one hand, the absorption depth of light in metals is more shallow in the visible than in the IR range. On the other hand, the absorption of the laser beam by the plasma-plume due to inverse Bremsstrahlung varying as $\lambda^{2}[6,7]$ and the absorption is higher in the IR range than in the visible. Hence, the ablative effect can be high in the visible range, whereas IR lasers induce a deeper and efficient heating of the target. The high energy of species in the plasma-plume favors the formation of NPs in the latter case. The laser plume undergoes a rapid spatial expansion, which is slowed down due to its compression in the surrounding atmosphere. Typical models of nanosecond laser ablation consist of several stages including the laser heating and evaporation of the target, the laser heating and expansion of the plasma plume and the condensation process giving rise to the formation of NPs $[8,9,10]$.

In femtosecond laser ablation, the laser pulse duration is shorter than the characteristic relaxation times and thus the laser-plume interactions are minimal or negligible $[11,5,12]$. 
In any case, for both nanosecond and femtosecond laser treatments, the ambient gas plays a key role in the process giving rise to the NPs formation. Insitu probing the plasma plume is of great interest to understand the mechanisms of NPs formation.

Third generation synchrotron radiation based Small Angle X-Ray Scattering (SAXS), allows in-situ probing for the presence of nano and mesoparticles to be done in complex media. In previous works, we have used SAXS to study particle size distributions in diffusion flames [13], microwave-generated fireballs [14], electrical arcs [15] and also in the plasma plume induced by nanosecond IR pulsed laser irradiation of titanium targets in air [16]. In the latter case, we showed the existence of at least two families of nanoparticles formed in the plasma plume. The smallest, with radii of gyrations of about 10nm, grow in the plume by condensation and then aggregate to form structures in the form of a necklace of about 55-75nm in size, depending upon the irradiance of the laser [16].

In this paper, we report new results obtained using SAXS on the SWING beam-line at the SOLEIL synchrotron. The aim was to study the influence of a reactive atmosphere on the formation of NPs in the plasma plume. For this, laser treatments and in-situ SAXS experiments were performed in an air-tight chamber which allowed the composition of the surrounding atmosphere to be controlled. In this way, various $\mathrm{O}_{2}-\mathrm{N}_{2}$ gas mixtures as well as common air were used. Moreover, the effect on different metal targets ( $\mathrm{Ti}, \mathrm{Al}, \mathrm{Ag}$ ) was also studied. For experiments in air the NPs thus formed were collected and studied ex-situ using transmission electron microscopy (TEM), X-ray diffraction (XRD) and Raman spectroscopy.

\section{Experimental details}

In this experiment, the size and the morphology of the nanoparticles were studied for different compositions of both the irradiated metal target ( $\mathrm{Ti}, \mathrm{Al}$, $\mathrm{Ag}$ ) and the surrounding atmosphere. Pure Ar, $\mathrm{O}_{2}-\mathrm{N}_{2}$ gas mixtures with differ- 
ent percentages of $\mathrm{O}_{2}$ and $\mathrm{N}_{2}$, and common air were used. The oxygen volume content in the gas mixture was varied from 0 to $20 \%$. A custom chamber (Fig. 1) was fabricated for this purpose. The target was placed on a motorized plate which provided a continuous displacement of the sample during the SAXS experiments in order to avoid any effects due to a modification of the target surface during the laser treatments.

The laser beam direction was kept fixed and perpendicular to the target surface. An optical window in BK7 transparent glass was used to reduce the absorption of the laser beam. Targets were irradiated with the fundamental harmonic of a Nd:YAG laser operating at $1064 \mathrm{~nm}$, with a pulse duration of $5 \mathrm{~ns}$ and a repetition rate of $20 \mathrm{kHz}$. The laser beam irradiance focused on the target was $1.2 \mathrm{GW} . \mathrm{cm}^{-2}$. In previous experiments with a similar laser source irradiating a titanium target in air, the general shape of the plume was found to be hemispherical, its height and width being about 2.8 and $5 \mathrm{~mm}$, respectively [17].

The x-ray synchrotron beam ( $80 \mu \mathrm{m}$ high and $300 \mu \mathrm{m}$ wide) passed through the chamber in a fixed direction, perpendicularly to the laser beam, 600 or $800 \mu \mathrm{m}$ above the target surface (for $\mathrm{Ti}$ and $\mathrm{Al}$, respectively) in order to probe the plasma plume. Mica windows were used to allow passage into and out of the chamber. The energy of the $\mathrm{x}$-rays was chosen to be $12 \mathrm{keV}$ to reduce absorption by the ambient air and the detector was placed $4 \mathrm{~m}$ away from the target plume. In this configuration, the measured scattering vector, $q=(4 \pi / \lambda) \sin (\theta / 2)$, where $\lambda$ and $\theta$ are the wavelength of the incident x-ray radiation and the scattering angle, respectively, covers the range from 0.0022 to $0.2 \AA^{-1}$ though in practice the upper limit is dominated by air scattering above $0.1 \AA^{-1}$. Since the particle size can be estimated to be $D \sim \pi / q$, NPs with sizes in the $3-140 \mathrm{~nm}$ range could be detected.

The preformed gas mixtures (or common air) were sent through the chamber during the SAXS experiments with a flow rate of 1 liter per minute. At the end of each run, the chamber was pumped to evacuate the gas and to avoid any NPs depositing on the target surface. Taking into account the gas flow in 
the chamber, a time of $50 \mu$ s between successive laser pulses and a duration of the plasma plume for a pulse roughly estimated in the microsecond range, the overalp of NPs formed by sucessive pulses can be neglected here. Measurements were made at different heights above the target surface but no significant difference in the NPs size was found.

The nanopowders formed during the pulsed laser irradiation of the targets in air could be collected and studied ex-situ using conventional TEM, XRD and micro-Raman spectroscopy. The TEM set-up was a $200 \mathrm{kV}$ JEOL $2100\left(\mathrm{LaB}_{6}\right)$ microscope. XRD patterns were recorded on a Siemens D5005 diffractometer using $\mathrm{Cu} \mathrm{K} \alpha$ radiation. Raman spectra were obtained in back-scattering configuration using an InVia Renishaw set-up. The excitation wavelength was 532 $\mathrm{nm}$ and the excitation power focused on the sample was about $55 \mu \mathrm{W}$ to avoid heating the samples.

\section{Results and discussion}

\subsection{In-situ SAXS studies}

Analysis of the scattering pattern was performed using the single level Beaucage unified exponential/power-law fitting function [18]:

$$
I(q)=G \exp \left(-\frac{q^{2} R_{g}^{2}}{3}\right)+B\left\{q^{-1}\left[\operatorname{erf}\left(\frac{q R_{g}}{\sqrt{6}}\right)\right]^{3}\right\}^{P}
$$

which has a Guinier exponential form at low $q$ and an associated powerlaw in the so-called Porod, high $q$ region. $R_{g}$ denotes the radius of gyration. $G, B$ and $P$ are the Guinier pre-factor, a surface area specific factor and the power-law exponent, respectively. To fit equation (1) to our data, the Small Angle Scattering (SAS) macro package from J. Ilavsky of the Advanced Photon Source has been used [19]. In the present case, all the background subtracted, scattered $\mathrm{x}$-ray intensities were successfully fitted using a one-level function. Typical experimental data and the corresponding fitted curve are shown in Fig. 2. 
In the SAXS measurements we were not able to see a Guinier region at low q but the TEM images taken ex-situ (see below) show that the primary particles are agglomerated into much larger structures. Indeed the slope of the data at low q in Fig. 2 is on the order of 1 which is consistent with a chain structure.

The size distribution of the particles can be characterized by the polydispersity index PDI $=B R_{g}{ }^{4} /(1.62 G)$ where PDI $=1$ for monodisperse spheres. For polydisperse spheres displaying a log-normal distribution with a standard deviation $\sigma$, the mean radius of the spheres is given by

$$
R=\sqrt{\frac{5}{3}} R_{g} \exp \left(-\frac{13 \sigma^{2}}{2}\right)
$$

where $\sigma=[(\ln P D I) / 12)]^{1 / 2}$.

Each individual background subtracted scattering intensity was analyzed as mentioned above. The averaged values of radii of gyration, polydispersity index and mean radius of spheres are shown in Table 1 as a function of the target (Al, $\mathrm{Ti}, \mathrm{Ag}$ ) for laser treatments in air. The values of $R_{g}$ and $R$ vary in the 2 - $7 \mathrm{~nm}$ range, both of them increase from $\mathrm{Al}$ to Ti and Ag. The polydispersity index, $\mathrm{PDI}$, is 5.0 for $\mathrm{Al}$ which corresponds to a log-normal distribution, whereas smaller values about 3 are found for $\mathrm{Ti}$ and $\mathrm{Ag}$ which indicate a narrower size distribution.

For $\mathrm{Al}$ and $\mathrm{Ti}$ targets, measurements were also performed under different surrounding atmospheres. For experiments made by using pure Ar gas, no scattering signal was observed. The chemical inactivity of Ar may explain the weak scattering signals. Only experiments using common air and $\mathrm{O}_{2}-\mathrm{N}_{2}$ gas mixtures allowed the analysis of the scattering pattern.

In fact, the reactivity of the ambient gas can play a key role in the condensation process giving rise the NPs formation process. Metal oxides have very high fusion/solidification temperatures, so metal oxide NPs are going to be formed at very high temperatures in the plasma plume. Pure metals have lower fusion/condensation temperatures. So, at the very high temperatures corresponding to the formation of metal oxide NPs they remain in the gas phase 
where nano-aggregates are going to be formed. Taking into account the expansion of the plasma plume, pure metal NPs will be formed far away from the place analyzed by SAXS. This can explain the absence of signal for the q range ( NPs size) chosen in these experiments.

For experiments performed using different $\mathrm{O}_{2}-\mathrm{N}_{2}$ gas mixtures, the results obtained for the mean radius of spheres, $\mathrm{R}$, as a function of the $\mathrm{O}_{2}$ percentage in the $\mathrm{O}_{2}-\mathrm{N}_{2}$ gas mixture are given in Figure 3 .

For the lowest concentration of $\mathrm{O}_{2}, R$ values are quite similar for $\mathrm{Al}$ and Ti targets, around $5 \mathrm{~nm}$. The increase of the $\mathrm{O}_{2}$ percentage in the $\mathrm{O}_{2}-\mathrm{N}_{2}$ gas mixture up to around $10 \mathrm{vol} \%$ induces a decrease of the radius of spheres for both targets, then $\mathrm{R}$ value is almost unchanged for higher percentages of $\mathrm{O}_{2}$ going up to 20 vol.\%. The decrease of $\mathrm{R}$ is smaller for the Ti target, $\mathrm{R}$ being $3.4 \pm 0.7 \mathrm{~nm}$ for a gas mixture containing $20 \mathrm{vol} \%$ of $\mathrm{O}_{2}$. This value is in agreement with that determined by SAXS experiments in air, $4.0 \pm 0.8 \mathrm{~nm}$. For the aluminum target, $\mathrm{R}$ is as low as $1.9 \pm 0.4 \mathrm{~nm}$ for a gas mixture containing 15 vol.\% of $\mathrm{O}_{2}$. This value is also in good agreement with that obtained for laser treatments in air, $2.6 \pm 0.5 \mathrm{~nm}$.

\subsection{Ex-situ observations}

For experiments in air, the powders thus formed could be collected and studied by XRD and Raman spectroscopy. Results are given in Table 1 for Al, Ti and $\mathrm{Ag}$ targets. In all the cases, we found the formation of metal oxides, but silver oxide was a minority phase in the NPs formed in air. Indeed, no experiments were done for silver targets in the presence of a gas mixtures containing lower percentages of $\mathrm{O}_{2}$. For the aluminum target, an oxynitride phase was also found. In the case of Ti target, NPs were mainly crystallized in the anatase phase of $\mathrm{TiO}_{2}$ as it was shown by Raman spectra where the characteristic Eg peak at $144 \mathrm{~cm}^{-1}$ was clearly identified. The rutile phase of $\mathrm{TiO}_{2}$ was mainly found in the biggest NPs.

Nanopowders deposited on a sampling plate during the pulsed laser irradiation of the targets were studied ex-situ by conventional TEM. In the case of $\mathrm{Al}$ 
targets (Fig. 4a), NPs were difficult to observe. The particles had a tendency to move and change under the influence of the electron beam linked to an insulator behavior and therefore they acquire a charge upon electron beam irradiation.

In the case of Ti targets, the NPs were easily observed by TEM. No problems due to the accumulation of charges were found. Both XRD patterns and Raman spectra have clearly shown that the NPs are composed of $\mathrm{TiO}_{2}$ mainly crystallized in the anatase phase. The semiconductive properties de titanium dioxide explain de capacity of this NPs to evacuate the charges. Fig. 4b shows a view of NPs formed in this case. The smooth and sharp interface with the medium seen in this view is consistent with SAXS results. It is also noticed that the primary particles are spherical as assumed in our analysis of the radius.

The experimental NP size distribution obtained in this case is shown in Fig. 4c. The log-normal distribution fitted to it displays a mean diameter equal to $10.7 \mathrm{~nm}$ which is in agreement with the mean diameter value of $8.0 \pm 1.6 \mathrm{~nm}$ obtained by SAXS (Table 1).

\subsection{Discussion}

In previous works $[16,20]$, hydrodynamic simulations have been used to explain the formation of NPs in the plasma-plume and even the mean size of NPs in the case of laser irradiation of titanium targets in ambient air. As we have shown here, the formation of metal oxide NPs is found for the three metal targets by irradiation in gas mixtures containing $\mathrm{O}_{2}$. However, the chemical reactivity of the metal target in the surrounding atmosphere cannot be taken into account by hydrodynamic simulations.

In order to address this point, we will take into account the stability of the different metal oxides $\left(\mathrm{M}_{x} \mathrm{O}_{y}\right)$ for the three targets studied here. Indeed, the equation of the oxidation reaction leading to the formation of $\mathrm{M}_{x} \mathrm{O}_{y}$ oxides can be written as: $x \mathrm{M}+y / 2 \mathrm{O}_{2}=\mathrm{M}_{x} \mathrm{O}_{y}$

The standard Gibbs free energy, $\Delta_{f} G^{0}$, for this reaction is given in Table 2 for the most stable metal oxide phases of $\mathrm{Al}, \mathrm{Ti}$ and $\mathrm{Ag}$. The corundum phase of aluminum oxide shows the highest absolute value of $\Delta_{f} G^{0}$, whereas that of 
silver oxide is very small. So, silver oxide is not stable at high temperatures. Titanium, with $\Delta_{f} G^{0}=-890 \mathrm{~kJ} . \mathrm{mol}^{-1}$ for the rutile phase of $\mathrm{TiO}_{2}$, displays an intermediate behavior between $\mathrm{Al}$ and $\mathrm{Ag}$.

According to hydrodynamic simulations, metal nano-droplets are formed in the plasma-plume by a condensation process during the expansion of the plasma plume. The insertion of oxygen in metal nano-droplets above a concentration threshold leads to the formation of the corresponding oxide. However, metal oxides are more refractory than metals. Hence their solidification temperature is higher than that of metals, and thus oxides become solids at higher temperatures. This process limits the coalescence of nano-droplets in the plasma-plume. Thus, metals forming very stable oxides give rise to small NPs.

\section{Conclusions}

The influence of the surrounding atmosphere on the formation of NPs in the plasma-plume generated by nanosecond pulsed laser irradiation of metal targets at ambient pressure and high repetition rate was studied by in-situ SAXS experiments in a custom chamber where it was flowed a preformed $\mathrm{O}_{2}$ $\mathrm{N}_{2}$ gas mixture. Moreover, experiments using common air were also done. The NPs thus formed in this latter case were collected and studied ex-situ by TEM, XRD and Raman spectroscopy.

For laser treatments of $\mathrm{Al}, \mathrm{Ti}$ and $\mathrm{Ag}$ targets in air, SAXS results showed the formation of NPs with mean radius varying from $2.6 \mathrm{~nm}$ for $\mathrm{Al}$ up to $5.3 \mathrm{~nm}$ for Ag. TEM observations confirmed these results. The presence of metal oxide or oxynitride phases in the collected nanopowders was shown by ex-situ x-ray diffraction and Raman spectroscopy analysis.

For laser treatments of $\mathrm{Al}$ and $\mathrm{Ti}$ targets under a controlled atmosphere, the percentage of $\mathrm{O}_{2}$ in a reactive $\mathrm{O}_{2}-\mathrm{N}_{2}$ gas mixture was increased up to 20 vol.\%. The oxidation reaction of metal nano-droplets in the plasma-plume was proposed as a mechanism limiting the coalescence of NPs and so the size of the NPs thus formed. Hence, the stability of metal oxides appears as being 
a key parameter determining the NPs size.

\section{Acknowledgments}

The authors would like to thank Synchrotron Soleil for experimental and financial assistance with this project. Thanks are also due to J. Decloux (SILLTEC) for the laser source, to METALOR for the silver sample and to Grand Chalon for financial support.

\section{References}

[1] I. Shupyk, L. Lavisse, J. M. Jouvard, M. C. Marco de Lucas, S. Bourgeois, F. Herbst, J. Piquemal, F. Bozon-Verduraz, M. Pilloz, Study of surface layers and ejected powder formed by oxidation of titanium substrates with a pulsed Nd:YAG laser beam, Appl. Surf. Sci. 255 (10) (2009) 5574.

[2] S. J. Henley, J. D. Carey, S. R. P. Silva, Laser-induced conversion of noble metal- island films to dense monolayers of spherical nanoparticles, Phys. Rev. B 72 (2005) 195408.

[3] D. Riabinina, E. Irissou, B. Le Drogoff, M. Chaker, D. Guay, Influence of pressure on the $\mathrm{Pt}$ nanoparticle growth modes during pulsed laser ablation, J. Appl. Phys. 108 (2010) 034322.

[4] P. M. Ossi, F. Neri, N. Santo, S. Trusso, Noble metal nanoparticles produced by nanosecond laser ablation, Appl. Phys. A 104 (2011) 829.

[5] S. Amoruso, N. N. Nedyalkov, X. Wang, G. Ausanio, R. Bruzzese, P. A. Atanasov, Ultrashort-pulse laser ablation of gold thin film targets: Theory and experiment, Thin Solid Films 550 (2014) 190.

[6] A. L. Thomann, A. Basillais, M. Wegscheider, C. Boulmer-Leborgne, A. Pereira, P. Delaporte, M. Sentis, T. Sauvage, Chemical and structural modifications of laser treated iron surfaces: investigation of laser processing parameters, Appl. Surf. Sci. 230 (2004) 350. 
[7] N. Ohtsu, K. Kodama, K. Kitagawa, K. Wagatsuma, Comparison of surface films formed on titanium by pulsed Nd:YAG laser irradiation at different powers and wavelengths in nitrogen atmosphere, Appl. Surf. Sci. 256 (2010) 4522 .

[8] E. Lescoute, L. Hallo, D. Hebert, B. Chimier, B. Etchessahar, V. T. Tikhonchuk, J. M. Chevalier, P. Combis, Experimental observations and modeling of nanoparticle formation in laser-produced expanding plasma, Phys. Plasmas 15 (2008) 063507.

[9] E. Lescoute, L. Hallo, B. Chimier, D. Hebert, V. T. Tikhonchuk, C. Stenz, J. M. Chevalier, J. L. Rullier, S. Palmier, Particles formation in an expanding plasma, Eur. Phys. J. - Special Topics 175 (2009) 159.

[10] A. Voloshko, J. P. Colombier, T. E. Itina, Comparison of laser ablation with spark discharge techniques used for nanoparticle production, Appl. Surf. Sci. 336 (2015) 143.

[11] P. K. Diwakar, S. S. Harilal, A. Hassanein, M. C. Phillips, Expansion dynamics of ultrafast laser produced plasmas in the presence of ambient argon, J. Appl. Phys. 116 (2014) 133301.

[12] S. Barcikowski, A. Hahn, A. V. Kabashin, B. N. Chichkov, Properties of nanoparticles generated during femtosecond laser machining in air and water, Appl. Phys. A-Mater. Sci. Process. 87 (2007) 47.

[13] J. B. A. Mitchell, S. di Stasio, J. L. Le Garrec, A. I. Florescu-Mitchell, T. Narayanan, M. Sztucki, Small angle x-ray scattering study of flame soot nanoparticle aggregation and restructuring, J. Appl. Phys. 105 (2009) 124904.

[14] E. Jerby, A. Golts, Y. Shamir, S. Wonde, J. B. A. Mitchell, J. L. Le Garrec, T. Narayanan, M. Sztucki, D. Ashkenazi, Z. Barkay, N. Eliaz, Nanoparticle plasma ejected directly from solid copper by localized microwaves, Appl. Phys. Lett. 95 (2009) 191501. 
[15] E. Carvou, J. L. Le Garrec, J. Perez, J. Praquin, M. Djeddi, J. B. A. Mitchell, Small angle x-ray scattering and electron microscopy of nanoparticles formed in an electrical arc, AIP Advances 3 (2013) 032139.

[16] L. Lavisse, J. L. Le Garrec, L. Hallo, J. M. Jouvard, S. Carles, J. Perez, J. B. A. Mitchell, J. Decloux, M. Girault, V. Potin, H. Andrzejewski, M. C. Marco de Lucas, S. Bourgeois, In-situ small-angle x-ray scattering study of nanoparticles in the plasma plume induced by pulsed laser irradiation of metallic targets, Appl. Phys. Lett. 100 (2012) 164103.

[17] L. Lavisse, P. Berger, M. Cirisan, J. M. Jouvard, S. Bourgeois, M. C. Marco de Lucas, Influence of laser-target interaction regime on composition and properties of surface layers grown by laser treatment of Ti plates, J. Physics D - Appl. Phys. 42 (2009) 245303.

[18] G. Beaucage, Approximations leading to a unified exponential power-law approach to small-angle scattering, J. Appl. Cryst. 28 (1995) 717

[19] J. Ilavsky, P. R. Jemian, Irena: tool suite for modeling and analysis of small-angle scattering, J. Appl. Cryst. 42 (2009) 347.

[20] M. Girault, L. Lavisse, M. C. Marco de Lucas, L. Hallo, D. Hebert, V. Potin, J. M. Jouvard, Modelling nanoparticles formation in the plasma plume induced by nanosecond pulsed lasers, Appl. Surf. Sci. 258 (2012) 9461. 


\section{List of Figures}

1 Schematic view of the chamber devoted to laser treatments under a controlled atmosphere and in-situ synchrotron scattering experiments. $(a) \ldots \ldots \ldots \ldots \ldots \ldots \ldots \ldots \ldots \ldots$ tor $q$ obtained for a Ti target during laser treatment in air. The experimental intensity (black line) is fitted (red line) in the $0.02-$ $0.09 \AA^{-1}$ range using a unified exponential/power-law function (eq.??) which is composed of a Guinier exponential law (blue dotted line) and a Porod power law (green line). (b) Particle size distribution obtained with the fitting parameters of the experimental SAXS intensity (green line). . . . . . . . . . . .

3 Variation of the mean radius of nanoparticle spheres, $\mathrm{R}$, determined by SAXS experiments as a function of the $\mathrm{O}_{2}$ percentage in the $\mathrm{O}_{2}-\mathrm{N}_{2}$ gas mixture for $\mathrm{Al}$ and Ti targets. The values of $\mathrm{R}$ obtained in the case of laser treatments of $\mathrm{Al}, \mathrm{Ti}$ and $\mathrm{Ag}$ targets in air are also shown. . . . . . . . . . . . . 16

4 (a,b) TEM image of nanopowders obtained by pulsed laser irradiation of $\mathrm{Al}$ and $\mathrm{Ti}$ targets in air, respectively. (c) Experimental

NP size distribution obtained in the case of a Ti target (statistics over $1013 \mathrm{NPs}$ ). The log-normal distribution fitted to it (mean diameter $\mathrm{D}=10.7 \mathrm{~nm}$ and standard deviation $\sigma=1.40$ ) and the $95 \%$ confidence band are also shown. . . . . . . . . . . . . . 


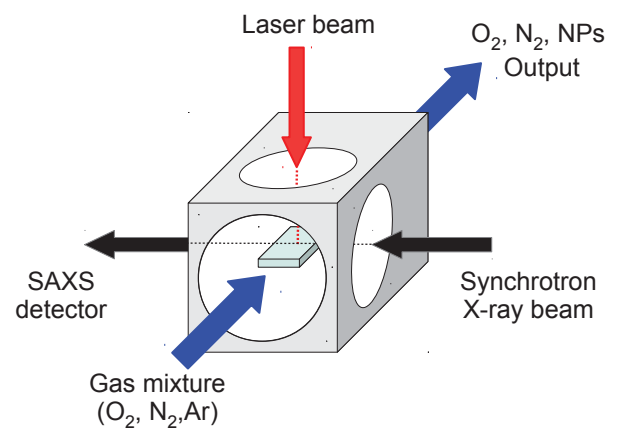

Figure 1: Schematic view of the chamber devoted to laser treatments under a controlled atmosphere and in-situ synchrotron scattering experiments. 

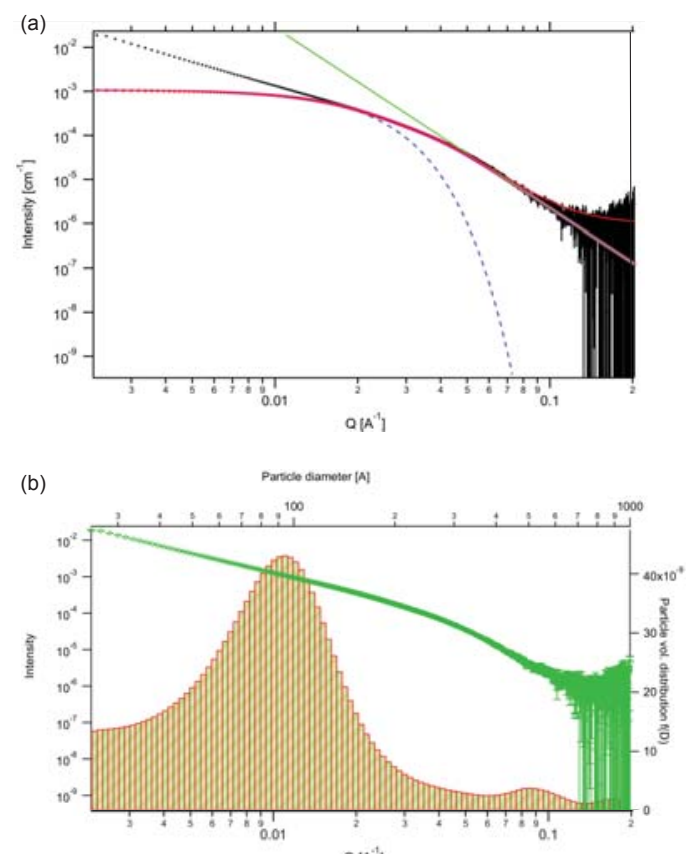

Figure 2: (a) Typical SAXS intensity, $I(q)$, as a function of scattering vector $q$ obtained for Ti target during laser treatment in air. The experimental intensity (black line) is fitted (red line) in the 0.02-0.09 $\AA^{-1}$ range using a unified exponential/power-law function (eq.??) which

line) (b) Particle size distribution obtained with the fitting parameters of the experimental SAXS intensity (green line). 


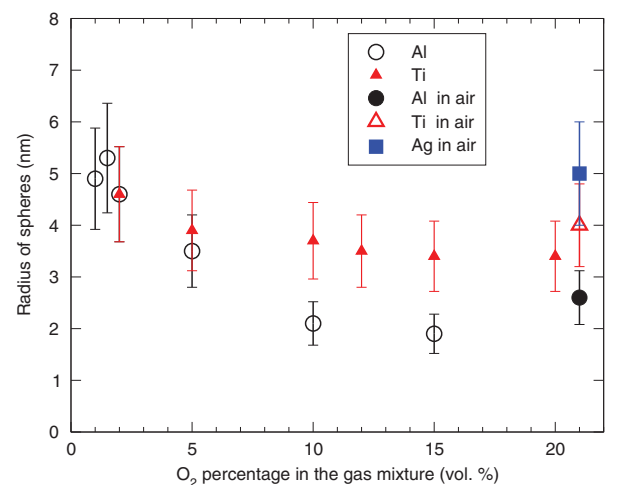

Figure 3: Variation of the mean radius of nanoparticle spheres, $\mathrm{R}$, determined by SAXS experiments as a function of the $\mathrm{O}_{2}$ percentage in the $\mathrm{O}_{2}-\mathrm{N}_{2}$ gas mixture for $\mathrm{Al}$ and $\mathrm{Ti}$ targets. The values of $\mathrm{R}$ obtained in the case of laser treatments of $\mathrm{Al}, \mathrm{Ti}$ and $\mathrm{Ag}$ targets in air are also shown. 


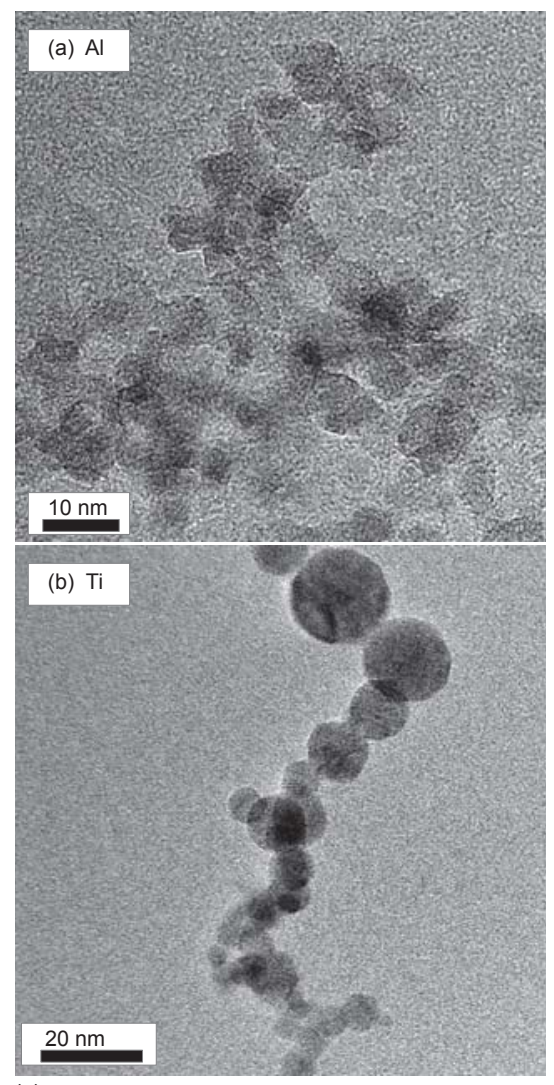

(c)

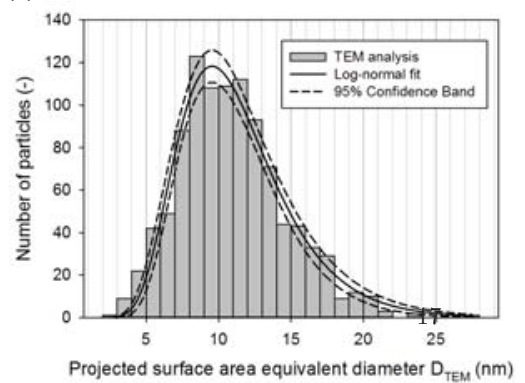

Figure 4: (a,b) TEM image of nanopowders obtained by pulsed laser irradiation of $\mathrm{Al}$ and

tion obtained in the case of

Ti target (statistics over $1013 \mathrm{NPs}$ ). The log-normal distribution fitted to it (mean diameter

$\mathrm{D}=10.7 \mathrm{~nm}$ and standard deviation $\sigma=1.40)$ and the $95 \%$ confidence band are also shown. 


\section{List of Tables}

1 Results of the fitting of SAXS experimental intensity for $\mathrm{Al}, \mathrm{Ti}$ and $\mathrm{Ag}$ irradiated in air by using the unified exponential/powerlaw function : radius of gyration $\left(R_{g}\right)$, polydispersity $(P D I)$ and mean radius $(R)$. The errors associated with the radius of gyration $\left(R_{g}\right)$ are on the order of $10 \%$. Those for the radius $(\mathrm{R})$ are on the order of $20 \%$. The compounds identified by XRD and Raman spectrosopy studies of the collected powders are also given. 19

2 Standard Gibbs free energy of $\mathrm{Al}, \mathrm{Ti}$ and $\mathrm{Ag}$ oxides. . . . . . . . 20 


\begin{tabular}{c||ccc||c} 
Target & $\begin{array}{c}R_{g} \\
(\mathrm{~nm})\end{array}$ & $P D I$ & $\begin{array}{c}R \\
(\mathrm{~nm})\end{array}$ & Powder's composition \\
\hline $\mathrm{Al}$ & 4.8 & 5.0 & 2.6 & $\mathrm{Al}, \mathrm{AlN}, \mathrm{Al}_{2.86} \mathrm{O}_{3.56} \mathrm{~N}_{0.44}$ \\
\hline $\mathrm{Ti}$ & 5.6 & 3.2 & 4.0 & $\mathrm{TiO}_{2}($ anatase, rutile) \\
\hline $\mathrm{Ag}$ & 7.0 & 2.8 & 5.3 & $\mathrm{Ag}, \mathrm{Ag}_{2} \mathrm{O}$
\end{tabular}

Table 1: Results of the fitting of SAXS experimental intensity for $\mathrm{Al}, \mathrm{Ti}$ and $\mathrm{Ag}$ irradiated in air by using the unified exponential/power-law function : radius of gyration $\left(R_{q}\right)$, polydispersity $(P D I)$ and mean radius $(R)$. The errors associated with the radius of gyration $\left(R_{g}\right)$ are on the order of $10 \%$. Those for the radius (R) are on the order of $20 \%$. The compounds identified by XRD and Raman spectrosopy studies of the collected powders are also given. 


\begin{tabular}{cccc} 
Metal & Oxide & Phase & $\begin{array}{c}\Delta_{f} G^{0} \\
\left(\text { kJ.mol }^{-1}\right)\end{array}$ \\
\hline $\mathrm{Al}$ & $\mathrm{Al}_{2} \mathrm{O}_{3}$ & $\alpha-\mathrm{Al}_{2} \mathrm{O}_{3}(\mathrm{R}-3 \mathrm{c})$ & -1582 \\
$\mathrm{Ti}$ & $\mathrm{TiO}_{2}$ & rutile $\left(\mathrm{P} 4_{2} / \mathrm{mnm}\right)$ & -890 \\
$\mathrm{Ag}$ & $\mathrm{Ag}_{2} \mathrm{O}$ & cubic $(\mathrm{Pn}-3 \mathrm{~m})$ & -11
\end{tabular}

Table 2: Standard Gibbs free energy of $\mathrm{Al}, \mathrm{Ti}$ and $\mathrm{Ag}$ oxides. 